Kong. Res. J. 1(2): 35-40, 2014

Kongunadu Arts and Science College, Coimbatore

\title{
INVESTIGATION ON VARIOUS PARAMETERS OF SOAPS AND DETERGENTS
}

\author{
Gunavathy N., T. Amalorpavathavitha, J.J. Anthoniammal, J. Gowri, P. Nithya, K. Radhamani, \\ K. Suganthi and K. Dhanalakshmi \\ Department of Chemistry, Nirmala College for Women, Coimbatore. \\ *Email: gunavathykrishnaprakash@yahoo.co.in
}

\begin{abstract}
Soap is a substance that dissolves in water to remove dirt from surfaces such as skin, textiles and other solids. Soaps are mainly used as surfactants for washing, bathing and cleaning. They are also used in textiles spinning and are important components of lubricants. The present study was carried out to assess the various properties of different soaps, in terms of $\mathrm{pH}$, basicity, emulsification, content of fat, washing property, moisture content, foaming capacity and hard water reaction. A cursory look at the obtained results reveals similarities in parameters in the selected soaps It can been concluded that the values determined are within the limits set by standards.
\end{abstract}

Keywords : Soaps, Detergents, pH, TFM, hard water reactions, foam capacity.

\section{INTRODUCTION}

The name of soap, after an ancient Roman legend, comes apparently from Mount Sapo, where animals were slaughtered. The rain had mixed fat, tallow and ashes on the Tiber. The women found that this mixture enhanced the work, and started to use the slity soil, moistened with a mixture of fat. Soap, in fact, is the oldest active substances, and has been used about 4500 years. For centuries, soap was the only one cleaning substance available. Historically, it has been claimed that the esteem of a country's civilization is based on consumption of soap. In the 18th century, because of the shortage of some raw materials, soap was a highly priced luxury, and only wealthy people could afford it. It became handy to other people only after the manufacture of sodium carbonate was developed (Schulze, 1968). At the end of the 19th century, the first soap powder for laundry was made using sodium silicate as a builder. Whereas the use of sodium or potassium carbonate leads to a hard or soft soap, respectively. The chemical nature of the lipophilic part of the soap plays by far the largest role in determining the performance of the finished soap (Viorica Popescu et al., 2011).

The first written record of soap can be seen in the writings of the Roman Pliny the Elder. He described the Phoenicians' synthesis of soap by using goat tallow and ashes. By the second centaury A. D, sodium carbonate was heated with lime (from limestone) to produce sodium hydroxide (lye). The sodium hydroxide was heated with animal fats or vegetable oils to produce soap (Bahl, 1991). Other societies made soap in much the same manner.
Soap (sodium salt of fatty acid) the oldest known surfactant has been used since the Egyptian era (Saad Moulay, 2011). It is now used mostly as toiletry soap bars for body cleansers and sometimes for fabric detergents and today for cleaning utensils. In detergents, soap is sometimes formulated as foam control agent. Direct saponification from fats was used initially to make soap but, today, soap is obtained by neutralizing fatty acids with $\mathrm{NaOH}$. As the salt of a weak acid (fatty acid) and strong base $(\mathrm{NaOH})$, soap is alkaline (pH 10) in aqueous solution, the alkalinity favours detergency but can cause skin irritation and hair damage. In addition, soap is not tolerant of hard water and forms scum with calcium and magnesium ions (Roila Awang et al., 2001). In the present study the various properties of soap like $\mathrm{pH}$, basicity, emulsification, content of fat, washing property, moisture content, foaming capacity and hard water reaction were evaluated.

\section{MATERIALS AND METHODS}

\subsection{Preparation of Samples}

The soaps analyzed were purchased from the departmental store. The bathing soap - Nature Power Herbal soap and Fair Beat, dish washing soap - Vim bar and Exo bar, fabric cleansing soap Power detergent and Sundari detergent (Figure 1), were made into small bits using a steel scrapper and stored in different air tight container.

Figure. 1. Soap samples scrapped into bits

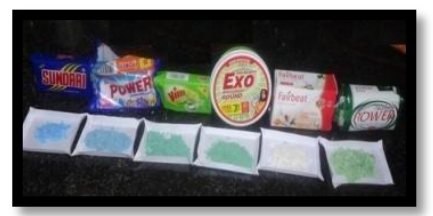




\subsection{Determination of $\mathrm{pH}$}

$10 \mathrm{~g}$ of the powdered soap was weighed and dissolved in distilled water in a $100 \mathrm{ml}$ volumetric flask. This was made up to prepare $10 \%$ soap solution (Jahagirdar 1994, Dalen, 2009). The pH of the soap solution was determined using Model ELICO $\mathrm{pH}$ meter.

\subsection{Determination of basicity}

$0.1 \mathrm{~g}$ of soap samples was dissolved in $5 \mathrm{ml}$ of ethanol. A few drops of the phenolphthalein were added (Blackburn et al., 1996). The appearance of the solution was noted.

\subsection{Determination of Emulsification}

$100 \mathrm{ml}$ of coconut oil was taken in the test tube and $10 \mathrm{ml}$ of distilled water was added and shaken well. $0.1 \mathrm{gm}$ of soap was added the above mixture. The appearance of the solution was noted.

\subsection{Determination of Total Fatty Matter (TFM)}

The soap samples were made into small slices. $5 \mathrm{~g}$ of thoroughly mixed soap sample was weighed, using an electronic balance, the weight was noted. The weighed soap samples were taken into a separating funnel and $30 \mathrm{ml}$ of hot water was added from a beaker and mixed well. Excess of $1: 1 \mathrm{HCl}$ was added to decompose the soap till acids floated as a clear layer on the top. $50 \mathrm{ml}$ of ether was added in the cold condition, mixed well and separated (Kundu et al., 1977).

The aqueous layer was taken in another separating funnel and extracted with ether. The combined ether extracts were washed thrice with water to remove mineral acids and the contents were collected in a previously weighed $100 \mathrm{ml}$ conical flask. The ether was allow to evaporated (with the contents) in a hot air oven to constant weight.

From the difference in weight, the \% of fatty matter in the analyzed soap samples was calculated using the relation (Viorica Popescu et al., 2011).

Fatty matter $(\%)=(B-A) / C \times 100$

Where,

A - Weight of the empty conical flask

B - Weight of the conical flask + Soap after drying

C - Weight of initial sample of soap.

\subsubsection{Determination of Washing Property}

Each of the soap samples were used to wash the hands. The observations were noted.

\subsubsection{Determination of Moisture Content}

$5 \mathrm{~g}$ of the scrapped soap samples were weighed in an electronic balance into a pre weighed petri dish and placed in a hot oven at $105^{\circ} \mathrm{C}$. It was then placed in the crucible in the desiccator and its content was weighed after cooling. The moisture content was found from the weight difference (MakMensa, 2011). The moisture content of the samples was calculated using the following equation.

$\% \mathrm{~W}=\mathrm{A}-\mathrm{B} / \mathrm{B} \times 100$

Where, $\% \mathrm{~W}=$ Percentage of moisture in the sample,

$A=$ Weight of wet sample (grams) and

$\mathrm{B}=$ Weight of dry sample (grams)

\subsubsection{Determination of Foaming Capacity}

6 conical flasks $(100 \mathrm{ml})$ were taken and numbered 1 to 6 . In each of these flasks equal amounts $(5 \mathrm{~g})$ of the samples of soap shavings were taken and $50 \mathrm{ml}$ of distilled water was added. Each conical flask was heated for few minutes to dissolve all the soap. In a test tube stand, six big clean and dry test tubes were taken and numbered them 1 to 6 . One $\mathrm{ml}$ of the soap solution was then poured in to the test tubes of corresponding number. $10 \mathrm{ml}$ of distilled water was then added to each test tube. Test tube no. 1 was then shaken vigorously ( 5 times). The foam was found to be formed in the empty space above the container. Stop watch was started immediately and the time taken for the disappearance of foam was noted

Similarly the other test tubes were shaken vigorously for equal number of times (i.e., 5 times) with approximately with the same force and the time taken for the disappearance of foam in each case was recorded.

The lesser the time taken for the disappearance of foam, the lower is the foaming capacity. The soap for which the time taken for disappearance of foam is highest has maximum foaming capacity and is the best quality soap among the soaps tested.

\subsubsection{Determination of Hard Water Reaction}

$1 \mathrm{~g}$ of the powdered soap sample was taken and warmed with $50 \mathrm{ml}$ of water in a $100 \mathrm{ml}$ beaker. When the clear solution was obtained, it was poured in to each of three test tubes. One of the three test tube with 10 drops of $5 \% \mathrm{CaCl}_{2}$ solution, one with 10 drops of $5 \%$ of $\mathrm{MgCl}_{2}$ solution and one with 10 drops of $5 \% \mathrm{FeSO}_{4}$ solution (Blackburn, 1996). These solutions stand until the other tests have finished. The observations were noted. 


\section{RESULTS AND DISCUSSIONS}

Most soaps and cleaners usually remove dirt adequately, but their use is not devoid of adverse side-effects (Beetseh, 2013). These adverse effects include damage to the barrier function of the skin, increased susceptibility to environmental irritants and antigens, skin irritation with erythema and edema, and reduction of the cosmetic qualities of the skin, such as moisture and smoothness. These changes are usually subtle, occurring slowly over time, and are most important in elderly and atopic patients. Often, the association of these problems with the use of a particular type of soap is overlooked. Skin dryness can be exacerbated by dry climate and the influence of hard water, which increases the irritant effect of soaps or detergents (Lourdes Baranda et al., 2002). Although it is important that the general population are aware of the potential of products used for body cleansing, fabric cleansing and dish washing, this information is not usually available therefore, it was decided to analyze the $\mathrm{pH}$, foaming capacity, moisture content, basicity, hard water reaction, emulsification, content of fat and washing property.

\section{1. $p H$ of Soaps}

Soap is a base and exact pH would be different depending on the soap. The $\mathrm{pH}$ level of soap can vary with the brand and with the function of the soap. However soap makers measure the acidity or alkalinity of soap by its $\mathrm{pH}$ level on a scale of 0 to 14 . The average $\mathrm{pH}$ levels in bath soaps range from 3.61 to 12.38 . For a general soap $\mathrm{pH}$ is from 5 to 8 and for hand soaps the $\mathrm{pH}$ is anywhere from 10 to 12 . A 2002 International Journal of Dermatology study found $\mathrm{pH}$ levels in bath soap ranging 3.61 to 12.38 . High $\mathrm{pH}$ soaps caused the most irritation. In liquid dish washing liquids, a $\mathrm{pH}$ in the range of about 7-8 (Dalen, 2009; Beetseh, 2013) .

The $\mathrm{pH}$ of the soap samples were determined using ELICO pH meter and it was found to be 7.3, 7.2, 8.1, 7.6, 7.8 and 7.7 for Nature power, Fair beat, Vim, Exo, Power and Sundari soap respectively. As soaps are more frequently used by general population, soaps with high irritation index should not used by individuals. The test samples had $\mathrm{pH}$ ranging from 7.3 to 8.1 which were well within the recommended levels.

\subsection{Basicity of soaps}

Soaps undergo a hydrolysis reaction in water. As a result, soap solutions tend to be alkaline. Detergents solutions on the other hand tend to be more neutral. Phenolphthalein indicator when in contact or presence of acid it will turn colorless and with base, it will turn into a pinkish violet color (Blackburn, 1996). When the solution of soap is treated with 2-3 drops of phenolphthalein, it is found to show no change, indicating that the selected soaps are found to be neutral.

\subsection{Emusification of soaps}

Soap is an excellent cleanser because of its ability to act as an emulsify agent. An emulsifier is capable of dispersing one liquid into another immiscible liquid. This means that while oil (which attracts dirt) does not naturally mix with water, soap can suspend oil/dirt in such a way that it can be removed.

For a soap to perform its cleaning activity it should be able to form emulsion in presence of oil. As a result of their molecular structures, soaps and detergents are both capable of emulsifying or dispersing oils and similar water-insoluble substances. Results showed that all the selected soap samples were found to have good cleansing action as they formed emulsion when shaken with oil.

\subsection{Total Fatty Matter (TFM) of soaps}

Total Fatty Matter (TFM) is one of the most important characteristics describing the quality of soap and it is always specified in commercial transaction. It is defined as the total amount of fatty matter, mostly fatty acids, that can be separated from a sample after splitting with mineral, usually hydrochloric acid. The fatty acids most commonly present in soap are oleic, stearic and palmitic acids and pure, dry, sodium oelate has TFM $92.8 \%$, while top quality soap noodles now increasingly used for making soap tables in small and medium size factories, are typically traded with a specification TFM $78 \%$ minimum, moisture $14 \%$ maximum. But besides moisture, finished commercial soap, especially laundry soap, also contains fillers used to lower its cost or confer special properties, plus emollients, preservatives.etc. and then the TFM can be as low as $50 \%$. Fillers which are usually dry powders, also make the soap harder, harsher on the skin and with greater tendency to become 'mushy' in water and so low TFM is usually associated with hardness and lower quality. In older days in Europe and in some countries, soap with TFM 75\% minimum was referred to as Grade I and 65\% minimum as Grade2 and less $60 \%$ Grade 3.

However according to the norms laid down by Bureau of Indian Standards (BIS) soaps are graded into three categories. Soaps containing TFM of $76 \%$ and above are Grade 1 . Soaps with TFM content of $70 \%$ and above but less than $76 \%$ are considered to be Grade 2 soaps and soaps having 
TFM content of $60 \%$ and above but less than $70 \%$ are graded as Grade 3.

Grade 2 and 3 soaps contain higher amount of fillers. Sometimes these fillers may even contain asbestos which can have an adverse effect on skin upon continued usage. They have tendency of getting mushy in water and tend to get consumed faster. Lower grade soaps have poorer lathering.

Grade 1 soaps on the other hand have a higher TFM content and provide very high cleansing efficiency while being gentle on skin.

Soap which is basically a cleansing product can be thus categorized based on it TFM content. Simply put, higher the TFM of soap better is its cleansing ability. Table 7 shows the TFM values of the test samples. All selected brands comply with the minimum requirement of total fatty matter as per the standard. All the selected sample except sundari soap can be categorized as grade 1 soap (Beetseh, 2013).

\subsection{Washing property of soaps}

In everyday life soap are used to wash dishes, clean clothes or keep our body presentable. Soap therefore has numerous applications in our daily life. One of its great values is keeping the hands out of significant risk (Warra, 2013). However the main purpose of soap is lost when these substances induce skin irritation and injury. Most soaps and detergents are alkaline and induce an increase in cutaneous $\mathrm{pH}$. In addition, repeated washing with soap may reduce the normal skin flora, leading to an increased colonization of the skin with coagulasenegative staphylococci; this effect has been linked to the skin $\mathrm{pH}$ caused by soaps (Mirela Moldovan, 2010; Lourdes Baranda et al., 2002).

\subsection{Moisture content of soaps}

Soaps often require a precise quantity of moisture in order to work at their most efficient levels; too little moisture leaves the soap too dry to use, while excessive moisture will make solid soaps more difficult to unmold and dry out. As common sense would dictate, one would expect a high level of moisture in liquid soap products. Moisture content affects soap making. The process of making soap (called "saponification") is highly dependent on the moisture level in the mixture (Simmons and Appleton, 2007). A major chemical ingredient in soap-making is alkali, such as lye, which reacts with fatty acid esters to produce neutral salts of fatty acids, the principal ingredient in soaps. The lower the water content of the reaction mixture, the higher the $\mathrm{pH}$ and the stronger the alkali. If the moisture level in the saponification reaction mixture is too high, the alkalinity will be reduced and the reaction will proceed too slowly. However, a high concentration of alkali chemicals is corrosive and damaging to people and equipment and must be handled with care. If the soap recipe does not have enough water the solid soap produced may form cracks. The moisture content of solid soap is adjusted by evaporation after the chemical reaction is complete.

There is no specific measurement of moisture content as per the national standard. It should not be too high or too low (A report of Consumer voice, 2014). Exo and Nature power contained the lowest moisture followed by Fair beat and sundari soap. Vim and power soap contained the maximum moisture.

\subsection{Foaming Capacity of Soaps}

Lather is the foam or the forth created by soap when stirred in water or while bathing or washing hands. It is an important parameter for acceptability of soaps. All the brands passed in the lather test. Fair beat alone was found to produce thick rubbery foam. The foam stability was determined by noting the time taken for disappearance of $2 \mathrm{~mm}$ of froth. From Table. 2 Fair Beat was found to have high foaming capacity of 3 minutes and 40 seconds. Power detergent soap showed the lowest foaming capacity of 1 minute.

\subsection{Hard water reaction of soaps}

The sodium and potassium salts of most carboxylic acids are water soluble. However, the calcium, magnesium, and iron salts are not. Thus when soaps are placed in hard water that contains such ions, an insoluble, curdy solid is formed. Often it has been seen that these results in the form of a bathtub ring or soap scum floating in bath or wash water. This process removes soap ions from solution, and decreases the cleaning effectiveness of soaps.

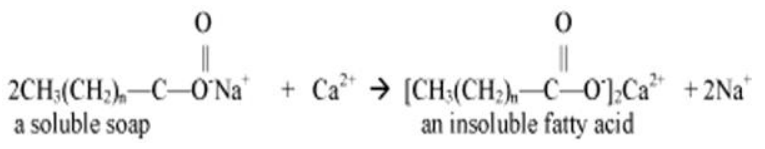

The calcium, magnesium, and iron forms of most detergents are more soluble in water than the corresponding soaps compounds (Blackburn, 1996). Consequently, detergents function almost as well in hard water as they do in soft water.

The selected soaps formed scum immediately / slowly in plenty / in scanty. All the soap samples formed scum when treated with $\mathrm{CaCl}_{2}$ and $\mathrm{FeSO}_{4}$. While only Nature Power and Fair beat 
formed scum with $\mathrm{MgCl}_{2}$. The results (Table. 3) show that Vim, Exo, Power and Sundari saop can be used even in hard water for cleaning purpose.

In the present study the effect of the soaps on the hands were determined by washing the hands with the selected soaps. All the soap samples were found to be soft on hand. It can be concluded these soaps are safe for use by public.

The results were sufficiently promising to warrant further investigation.

\section{CONCLUSION} cleansers.

All the samples were observed to be good

- $\mathrm{pH}$ of soap samples were found to be in the neutral range $7.2-8.1$.

- All samples were found to have neutral basicity.

- All the soap samples formed emulsion when shaken with oil.

- The TFM values ranged from 63 to 80 which were well within the standard values

- All the soap samples were found to be soft on hand while washing.

- Moisture content was in the range $6.50 \%$ to $22.90 \%$.

- Fair beat soap showed high foaming capacity of 340 ' minutes. Power detergent soap showed the lowest foaming capacity with 1 minute as the time taken for disappearance of $2 \mathrm{~mm}$ of soap froth.

- In hard water reaction all the soap samples formed scum when treated with $\mathrm{CaCl}_{2}$ and $\mathrm{FeSO}_{4}$ while only Nature power and Fair beat formed scum with $\mathrm{MgCl}_{2}$.

The results further indicate that good soaps are not characterized by their fragrance or appearance, nor by the place in which they are sold, but by their properties the exhibit.

\section{REFERENCES}

A report from Consumer Voice. (2014). Toilet soaps. 13-20.

Bahl, B.S. and Arun Bahl, (1991). Advanced Organic Chemistry, S. Chand and Company, NewDelhi. 644-698.

Beetseh, C.I. and M.K. Anza, (2013). Chemical characterization of local black soap (Chahul Mtse) made by using cassava peels ashes (alkali base) and palm oil in North Central zone of Nigeria. Civil Environl. Res. 3(4): 82-93.

Blackburn et al., (1996). Preparation and properties of a soap. Austin Peay State University Department of Chemistry CHEM 1021. Revision
SP11 Page 1 of 7. Adapted from Blackburn et al., Laboratory Manual to Accompany World of Chemistry, 2nd ed. (Saunders College Publishing: Fort Worth).

Dalen, M.B. and P.A. Mamza, (2009). Some physicchemical properties of prepared metallic soapdriers of Aluminum, Copper and Zinc. Science World Journal. 4(3): 7-9.

Jahagirdar, D.V, (1994). Experimental in Chemistry. Himalaya Publishing House, 237 - 239.

Kundu, M.K. A.T. Deb and S.P. Gupta, (1977). A simple rapid method for direct determination of Total Fatty Matter in Soaps. Fette, Seifen, Anstrichmittel. 79(7): 285-288.

Lourdes Baranda, Roberto Gonzalez-Amaro, Bertha Torrres-Alverez, Carmen Alvarez and Victoria Ramirez, (2010). Correlation between pH and irritant effect of cleansers marketed for dry skin. Paper presented at the $6^{\text {th }}$ edition of Colloque Franco-Roumain de Chimie Appliquee, COFrRoCA.

Mak-Mensa, E.E. and C.K. Firempong, (2011). Chemical characteristics of toilet soap prepared from neem (Azadirachta indica A.Juss) seed oil. Asian J. Plant Sci. Res. 1(4): 1-7.

Mirela Moldovan and Alina Nanu, (2010). Influence of cleaning product type on several skin parameters after single use. Farmacia. 58(1):29-37.

Roila Awang, Salmiah Ahmad and Razmah Ghazali, (2001). Properties of sodium soap derived from palm-based dihydroxy stearic acid. J. oil palm Res. 13(2): 33-38.

Saad Moulay, Ahmed Chalane and Zahia Ouad-Feul, (2011). Palm stearin in the soap process. Natura Montenegrina (Podgorica). 10(3): 335346.

Schulze, E.L., (1968). Literature of soaps and synthetic detergents. Lit. Cheml. Technol. Chapter 12: 231-248.

Simmons, W.H and H.A. Appleton, (2007). The Handbook of soap manufacture. [EBook \# 217241].

Viorica Popescu, Alina Soceanu, Simona Dobrinas, Gabriela Stanciu and Danut Tiberiu Epure. (2011). Quality control and evaluation of certain properties for soaps made in Romania. Scientific Study Res. 12(3): 257-261.

Warra, A.A, (2013). A report on soap making in Nigeria using indigenous technology and raw materials. Afr. J. Pure Appl. Chem. 7(4): 139145. 
Table 1. Different Parameters of soap samples

\begin{tabular}{lcccccc}
\hline \multicolumn{1}{c}{ Soap sample } & $\mathrm{pH}$ & Basicity & Emulsification & TFM & $\begin{array}{c}\text { Washing } \\
\text { property }\end{array}$ & $\begin{array}{c}\text { Moisture } \\
\text { content (\%) }\end{array}$ \\
\hline Nature Power & 7.3 & Neutral & Emulsion formed & 77 & Soft & 9.60 \\
Fair beat & 7.2 & Neutral & Emulsion formed & 80 & Soft & 12.40 \\
Vim & 8.1 & Neutral & Emulsion formed & 78 & Soft & 22.90 \\
Exo & 7.6 & Neutral & Emulsion formed & 79 & Soft & 6.50 \\
Power & 7.8 & Neutral & Emulsion formed & 75 & Soft & 21.78 \\
Sundari & 7.7 & Neutral & Emulsion formed & 63 & Soft & 18.74 \\
\hline
\end{tabular}

Table 2. Foaming capacity of soap samples

\begin{tabular}{|c|c|c|c|c|}
\hline \multirow{2}{*}{$\begin{array}{l}\text { Name of the soap } \\
\text { sample }\end{array}$} & \multirow{2}{*}{$\begin{array}{l}\text { Volume of soap } \\
\text { solution } \\
\text { (ml) }\end{array}$} & \multirow{2}{*}{$\begin{array}{l}\text { Volume of water } \\
\text { added } \\
\text { (ml) }\end{array}$} & \multicolumn{2}{|c|}{$\begin{array}{l}\text { Time taken for disappearance of } 2 \mathrm{~mm} \text { of } \\
\text { soap froth }\end{array}$} \\
\hline & & & Minutes & Seconds \\
\hline Nature power & 1 & 3 & 3 & 2 \\
\hline Fair beat & 1 & 3 & 3 & 40 \\
\hline Vim & 1 & 3 & 2 & 00 \\
\hline Exo & 1 & 3 & 2 & 10 \\
\hline Power & 1 & 3 & 1 & 00 \\
\hline Sundari & 1 & 3 & 1 & 20 \\
\hline
\end{tabular}

Table 3 Hard water reaction of Soap samples

\begin{tabular}{|c|c|c|c|c|}
\hline \multirow{2}{*}{ S.No. } & \multirow{2}{*}{$\begin{array}{c}\text { Name of the soap } \\
\text { sample }\end{array}$} & \multicolumn{3}{|c|}{ Hard water reaction } \\
\hline & & $\mathrm{CaCl}_{2}$ & $\mathrm{MgCl}_{2}$ & $\mathrm{FeSO}_{4}$ \\
\hline 1 & Nature Power & $\begin{array}{l}\text { Scum formed in } \\
\text { plenty }\end{array}$ & $\begin{array}{l}\text { Scum formed very slowly } \\
\text { and scanty }\end{array}$ & $\begin{array}{l}\text { Scum formed immediately } \\
\text { and plenty }\end{array}$ \\
\hline 2 & Fair Beat & $\begin{array}{l}\text { Scum formed slowly } \\
\text { and plenty }\end{array}$ & $\begin{array}{l}\text { Scum formed very slowly } \\
\text { and scanty }\end{array}$ & $\begin{array}{l}\text { Scum formed immediately } \\
\text { and plenty }\end{array}$ \\
\hline 3 & Vim & $\begin{array}{l}\text { Scum formed and } \\
\text { Scanty }\end{array}$ & No scum formed & $\begin{array}{l}\text { Scum formed immediately } \\
\text { and plenty }\end{array}$ \\
\hline 4 & Exo & $\begin{array}{l}\text { Scum formed and } \\
\text { Scanty }\end{array}$ & No scum formed & $\begin{array}{l}\text { Scum formed immediately } \\
\text { and plenty }\end{array}$ \\
\hline 5 & Power & $\begin{array}{l}\text { Scum formed and } \\
\text { Scanty }\end{array}$ & No scum formed & $\begin{array}{l}\text { Scum formed slowly and } \\
\text { scanty }\end{array}$ \\
\hline 6 & Sundari & $\begin{array}{l}\text { Scum formed slowly } \\
\text { and plenty }\end{array}$ & No scum formed & $\begin{array}{l}\text { Scum formed slowly and } \\
\text { scanty }\end{array}$ \\
\hline
\end{tabular}

